\title{
PENGARUH MODEL PEMBELAJARAN MIND MAPPING TERHADAP HASIL BELAJAR SIS WA KELAS X PADA MATA PELAJARAN GEOGRAFI DI SMA NEGERI 2 KIKIM SELATAN TAHUN PELAJARAN 2019/2020
}

\author{
Yanda Nauri $^{\bowtie}$, Dr. Misdalina, Helfa Septinar. \\ Universitas PGRI Palembang, Indonesia.
}

\section{Info Artikel}

Sejarah Artikel: Disubmit Oktober 2019 Direvisi Desember 2019

Diterima Desember 2019

\section{Keywords:}

Mind mapping learning model towards and learning outcomes in geography.

\begin{abstract}
Abstrak
Rumusan masalah dalam penelitian ini adalah pengaruh model Pembelajaran mind-mapping terhadap hasil belajar siswa kelas X pada mata pelajaran geografi di SMA Negeri 2 Kikim Selatan. Penelitian ini bertujuan untuk mengetahui ada atau tidak ada pengaruh model pembelajaran mind mapping terhadap hasil belajar siswa kelas X pada mata pelajaran geografi di SMA Negeri 2 Kikim Selatan. Metode penelitian yang yang digunahkan adalah metode pendekatan kuantitatif dengan metode eksprimen dengan teknik pengumpulan data diperoleh menggunakan observasi, tes, dan dokumentasi. Nilai ratarata hasil belajar siswa di kelas eksperimen dapat dikategorikan baik yaitu 76,45 dengan menggunakan model mind mapping, sedangkan nilai rata-rata hasil belajar kelas control dengan tidak menggunakan model mind mapping dapat dikategorikan cukup dengan rata-rata hasil belajar siswa adalah 61,29 . Berdasarkan perhitungan, diperoleh $t_{\text {hitung }}>t_{\text {tabel }}=6,369>1,683$ yaitu $t_{\text {hitung }}=6,369 \mathrm{dan} t_{\text {tabel }}=1,68$ maka terima hipotesis (ha) yang berarti " Ada pengaruh model pembelajaran mind mapping terhadap hasil belajar siswa kelas X pada mata pelajaran geografi di SMA Negeri 02 Kikim Selatan.
\end{abstract}

\section{Abstract}

The formulation of the problem in this study is the influence of the mindmapping learning model on the learning outcomes of class X students in geography in SMA 2 Kikim Selatan. This study aims to determine whether or not there is an influence of mind mapping learning models on class X student learning outcomes in geography subjects at SMA Negeri 2 Kikim Selatan. The research method used is a quantitative approach to the method of experimentation with data collection techniques obtained using observation, tests, and documentation. The average value of student learning outcomes in the experimental class can be categorized well that is 76.45 by using a mind mapping model, while the average value of learning outcomes of the control class by not using a mind mapping model can be categorized sufficiently with the average student learning outcomes is 61,29 . Based on calculations, obtained t arithmetic $>$ t table $=6.369>1.683$ ie t arithmetic $=6.369$ and $t$ table $=1.68$ then accept the hypothesis (ha) which means "There is an influence of mind mapping learning model on class X student learning outcomes in geography subjects at 02 Kikim Selatan High School.

(C) 2020 UniversitasNegeri Semarang

\begin{tabular}{lr}
\hline Alamatkorespondensi: & ISSN 2548-4641 \\
9 Ulu, KecamatanSeberangUlu I, Kota Palembang, Sumatera Selatan & E-ISSN 2548-4648 \\
30116 & \\
E-mail: Yandanauri02@gmail.com &
\end{tabular}




\section{PENDAHULUAN}

Pendidikan lebih memfokuskan perubahan tingkah laku manusia, yang konotasinya pada pendidikan etika. Di samping itu, pendidikan juga lebih menekankan aspek produktivitas dan kreatifitas manusia sehingga mereka dapat berperan serta berprofesi dalam kehidupan masyarakat (Anas Salahudin, 2011:20).

Pendidikan adalah usaha sadar yang dilakukan oleh keluarga, masyarakat, dan pemerintah, melalui kegiatan bimbingan, pengajaran, dan/atau latihan, yang berlangsung di sekolah dan diluar sekolah sepanjang hayat, untuk mempersiapkan peserta didik agar dapat memainkan peranan dalam berbagai lingkungan hidup secara tepat di masa yang akan datang. Pendidikan adalah pengalaman- pengalaman belajar terprogram dalam bentuk pendidikan formal, non - formal, dan informal di sekolah, yang berlangsung seumur hidup yang bertujuan optimalisasi pertimbangan kemampuan kemampuan individu, agar dikemudian hari dapat memainkan peranan hidup secara tepat ( Redja Mudyahardjo, 2014:11).

Saat ini, sering terjadi perubahanperubahan sistem pendidikan di Indonesia. Perubahan-perubahan itu terjadi dikarenakan telah dilakukan berbagai usaha pembaharuan dalam pendidikan yang dilakukan oleh Mentri pendidikan, mulai dari kurikulum tahun 1952, 1964, 1968, 2004, 2006, dan 2013

Namun pada permasalahannya guru sering kali tidak menerapkan pembelajaran yang menarik sehingga guru hanya mengajar dengan metode yang mudah bagi mereka. Yaitu metode ceramah dalam metode ceramah guru hanya menjelaskan secara lisan. Berdampak pada hasil belajar siswa yang semakin hari nilainya turun, siswa tidak tertarik dalam kegiatan belajar mengajar karena mereka hanya menerima informasi, mengingat, menghafal, dan ditambah lagi fasilitas yang ada di sekolahan tidak lengkap dikatakan tidak lengkap fasilitas belajar karena infokus yang ada disekolah hanya ada satu dan akibatnya guru harus bergantian untuk menggunakan infokus tersebut. Dan itulah membuat guru lebih dominan menggunakan metode ceramah, akibatnya rasa bosan di dalam diri siswa, bukan kah guru adalah pusat dari siswa karena guru mentransfer ilmu kepada siswa jadi siswa hanya menerima informasi dari guru tersebut. Sebagai seorang guru kita harus memecahkan masalah tentang rendahnya hasil belajar siswa salah satu cara mengatasinya yaitu menerapkan model pembelajaran yang dapat menciptakan suasana yang menyenangkan, di mana belajar sambil bermain sehingga siswa merasa tidak tegang, dalam proses pembelajaran, yang dapat membuat siswa aktif sehingga dapat meningkatkan hasil belajar siswa. Salah satu caranya yaitu model pembelajaran yang digunakan oleh guru adalah model pembelajaran mind mapping yang dapat mendorong siswa untuk lebih aktif dalam proses belajar.

Dari uraian diatas guru di tuntut untuk mempunyai model pembelajaran bervariasi agar siswa lebih tertarik belajar dan hasil belajar siswa mengalami peningkatan dari sebelumnya. Peneliti ingin menerapkan model pembelajaran Mind Mapping karena teknik mencatat yang menonjolkan sisi kreativitas sehingga efektif dalam memetakan pikiran untuk menguasai materi yang disajikan, dan sangat cocok untuk mereview pengetahuan siswa. Mind Mapping adalah model pembelajaran yang mempelajari konsep atau teknik mengingat sesuatu dengan bantuan mind map (menggunakan peta konsep, pencatatan materi belajar dituangkan dalam bentuk diagram yang membuat simbol, kode, gambar, dan warna yang saling berhubungan) sehingga kedua bagian otak manusia dapat digunakan secara maksimal di mana hal ini diharapkan mampu membantu kontribusi positif dalam proses pembelajaran, dan diharapkan memberikan ide yang bervariatif (Wahyudin Zarkasyi,2015:76).

Kelebihan menggunahkan model Mind Mapping dalam pembelajaran yaitu cepat ke point yang dituju, mudah dilihat dan dirujuk kembali, cocok untuk pembicaraan yang takrumit dan panjang.Kekurangan menggunahkan model Mind Mapping dalam 
pembelajaran yaituboros kertas, terkadang sulit mengingat point-poin sekunder, tidak cocok untuk obrolan singkat.

Berdasarkan data yang didapat peneliti dari guru di SMA Negeri 02 Kikim Selatan, terlihat selama dalam proses belajar mengajar terdapat sejumlah siswa yang kurang semangat ketika mengikuti pembelajaran. Hal ini disebabkan oleh guru lebih banyak memberi materi ceramah, sehingga mengakibatkan siswa tidak tertarik belajar. Akibatnya hasil belajar siswa kurang mencapai Kriteria Ketuntasan Minimum (KKM) 75 dari mata pelajaran geografi hanya $50 \%$ siswa yang tuntas standar KKM tersebut. Dengan menggunakan model mind mapping tersebut diharapkan nanatinya hasil belajar siswa lebih maksimal.

\section{METODE PENELITIAN}

Penelitian ini menggunakan metode pendekatan kuantitatif dengan metode eksperimen. "Metode penelitian eksprimen merupakan penelitian yang digunakan untuk mencari pengaruh perlakuan tertentu terhadap yang lain dalam kondisi terkendali"(Sugiyono,2016;72).

Dalam melaksanakan pelaksanaan penelitian ini ada dua kelas, yaitu kelas eksperimen dan kelas kontrol. Kelas eksperimen merupakan kelas yang di beri perlakuan dengan menggunakan Model Mind Mapping sedangkan kelas kontrol merupahkan kelas yang tidak diberikan perlakuan dengan menggunakan Model Mind Mapping melainkan menggunakan metode konvensional.

Penelitian ini berlokasi di SMA Negeri 02

Kikim Selatan yang berada dijalan Desa nanjungan Kec. Kikim Selatan Kabupaten Lahat. Penelitian ini dilaksanahkan selama 1 bulan pada bulan Agustus Waktu yang diperlukan untuk penelitian ini dapat berubah sesuai kebutuhan.

Populasi dalam penelitian ini adalah seluruh siswa kelas X IPS yang terdiri dari 2 kelas dengan jumlah keseluruhan 62 siswa. Sampel dalam penelitian ini diambil menggunakan teknik simple random sampling (sampel acak). Sampel dalam penelitian ada dua kelas yaitu kelas eksperimen X IPS 1 dengan jumlah 31 siswa diberi perlakuan menggunakan model mind mapping dengan materi konsep geografi dan kelas kontrol X IPS 2 dengan jumlah 31 siswa tidak tidak menggunakan model mind mapping dengan materi konsep geografi. Dari penelitian ini diperoleh data berupa hasil tes belajar siswa dengan diberi soal test berjumlah 20 butir soal pilihan ganda yang telah diuji validitas dan reliabilitasnya.

Teknik pengumpulan data dalam penelitian ini menggunahkan observasi, tes, dan dokumentasi. Analisis data dalam penelitian ini menggunakan uji normalitas, homogenitas, dan uji hipotesis.

\section{HASIL DAN PEMBAHASAN}

Penelitian ini dilaksanahkan di SMA Negeri 2 Kikim Selatan yang berada di Desa Nanjungan, Kecamatan Kikim Selatan Kabupaten Lahat.

Dari pelaksanaan penelitian dikelas eksprimen dan dikelas kontrol tersebut, pada kelas eksprimen yang menggunakan mind mapping siswanya aktif dalam kegiatan belajar mengajar. Bisa kita lihat dari gambar di bawah ini

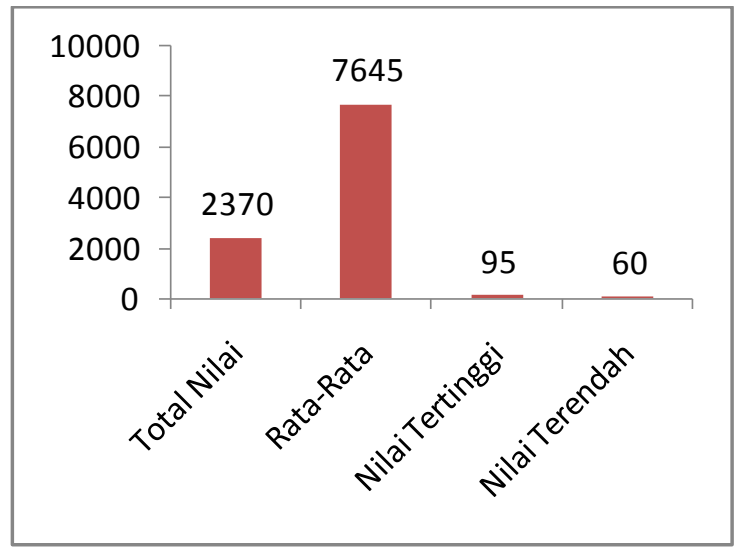

Gambar 1. Hasil Nilai Eksprimen

Sedangkan pada kelas kontrol yang tidak menggunakan model mind mapping, dalam kegiatan belajar mengajar siswanya cenderung 
hanya mendengar, mengiat, dan menghafal, terbukti dari gambar 2 .

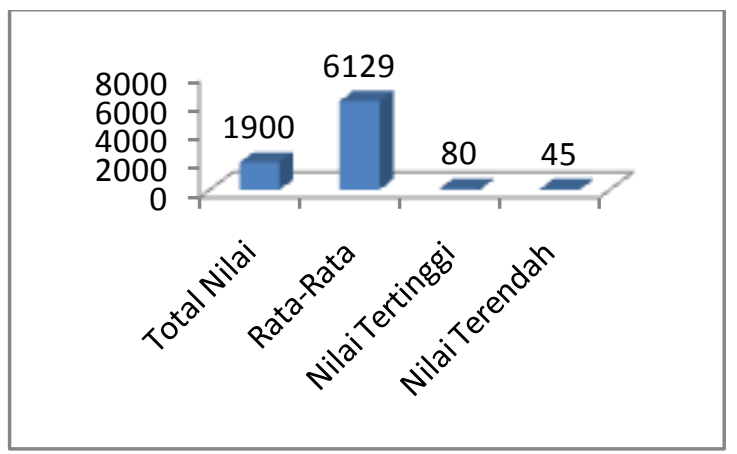

Gambar 2. Hasil Nilai Kontrol

Terdapat pengaruh model pembelajaran mind mapping terhadap hasil belajar siswa kelas $\mathrm{X}$ pada mata pelajaran geografi di SMA Negeri 02 Kikim Selatan.

Berdasarkan hasil yang telah diperoleh dari penelitian, menunjukkan bahwa model pembelajaran mind mapping atau kelas eksprimen yang diberihkan perlakuan kelompok memiliki nilai rata-rata yang lebih tinggi dibandingkan dengan nilai rata-rata kelas kontrol yang tidak diberi perlakuan dengan model pembelajaran konvensional.

Berdasarkan hasil perhitungan uji normalitas data pada kelas eksperimen diperoleh data normal karena nilai $\mathrm{Km}$ sebesar $-0,05$ harga ini terletak antara (-1) dan (1) dan kelas kontrol juga diperoleh data normal karena nilai $\mathrm{Km}$ sebesar $-0,12$ harga ini terletak antara (-1) dan (1).

Kemudian dilakukan Uji homogenitas data menggunakan uji barlett, uji homogenitas data dalam peneliatian ini digunakan taraf nyata $5 \%$ dengan $\mathrm{dk}=1$ diperoleh $\mathrm{X}_{\text {tabel }}^{2}=3,841 \mathrm{dan}$ $\mathrm{X}^{2}{ }_{\text {hitung }}=0,161$. Diketahui syarat homogen jika $\mathrm{X}^{2}{ }_{\text {hitung }}<\mathrm{X}_{\text {tabel }}^{2}$, sampel berasal dari populasi homogen karena, $\mathrm{X}^{2}{ }_{\text {hitung }}<\mathrm{X}_{\text {tabel }}{ }^{2}(0,161<3,841)$.

Dari hasil perhitungan diatas tahap selanjutnya pengujian hipotesis penelitian dengan menggunakan rumus uji-t. Diperoleh $t_{\text {hitung }}$ yaitu 6,369 , dibandingkan dengan $t_{\text {tabel }}$ 1,683 untuk $\mathrm{dk}=\mathrm{n} 1+\mathrm{n} 2-2=60$ dengan taraf signifikan $5 \%$ dengan demikian $t_{\text {hitung }}>t_{\text {tabel. }}$. Berarti Ha diterima dan Ho ditolak.Maka dapat disimpulkan bahwa terdapat pengaruh model pembelajaran mind mappingterhadap hasil belajar siswa kelas X pada mata pelajaran geografi di SMA Negeri 02 Kikim Selatan.

Model pembelajaran mind mapping Shoimin (2014: 105), "Model pembelajaran mind mapping adalah model pembelajaran yang meminta siswa untuk membuat mind map (peta pikiran), sehingga memungkinkan siswa mengidentifikasi dengan jelas dan kreatif apa yang telah dipelajari atau apa yang tengah direncanakan". Pada model ini siswa diminta kreatif dalam menggambar supaya mudah diingat dalam materi tersebut. Dalam strateginya teknik pemanfaatan keseluruhan otak untuk mencatat dengan cara mengelompokkan materi yang dipelajari agar lebih kreatif dan efektif untuk mengingat materi pelajaran, dan dalam menggambar inilah siswa tidak mengalami kejenuhan dalam belajar sehingga siswa tertarik dalam belajar.

Dalam proses kegiatan belajar pada penelitian ini, siswa dibagi menjadi 6 kelompok dimana masing-masing kelompok beranggotakan 4 Setelah siswa duduk dengan kelompoknya masing-masing peneliti membagikan soal kepada siswa untuk di diskusikan oleh siswa. Pada tahap ini siswa mulai menggorganisasikan ide-ide mereka untuk memahami masalah yang terdapat pada soal ysng diberikan peneliti seperti tentang apa yang diketahui dan apa yang ditanyakan dengan bimbingan guru, dimana pada tahap ini kelompok siswa dituntun dalam menyelesaikan permasalahan yang dihadapi. Selanjutnya setelah siswa memahami masalah siswa memikirkan kembali, mendalami dan menggali informasi yang sudah didapat dan dilaksanakan dalam kegiatan kelompok siswa. Sehingga pada tahap inilah siswa menyusun rencana penyelesaian masalah dan melaksanakan penyelesaiannya dengan bimbingan peneliti.

Dari tahapan-tahapan inilah siswa yang tadinya pasif dapat menjadi lebih aktif hal ini dikarenakan siswa melakukann diskusi bersama dengan kelompok belajarnya. Selain itu dalam siswa lebih mampu untuk mengerjakan permasalahan yang ada dengan bantuan teman 
sekelompok. Setelah siswa selesai mengerjakan soal yang diberikan peneliti peneliti membimbing siswa untuk melakukan pengecekan kembali hasil diskusi yang telah diperoleh dan mempresentasikannya. Pada proses siswa mempresentasikan hasil diskusi inilah siswa dapat memberikan tanggapan serta kesimpulan dari masalah tersebut. Penelitian ini belum didukung karna pada materi konsep geografi belum ada peneliti yang menggunakan materi ini.

Terdapat perbedaan hasil belajar baik itu tinggi, sedang, rendah, pada penelitian ini.Karena yang telah dilakukan oleh peneliti pada pertemuan pertama siswa mulai memahami materi, pertemuan kedua siswa mulai menunjukan hasil pembelajaran yang hampir mencapai penguasaan materi, dan ketiga siswa mulai menguasai materi pembelajaran yang dimana ditunjukan pada pemberian soal kepada siswa nilai yang didapatkan, pada pertemuan keempat peneliti memberikan angket kepada siswa pada akhir pembelajaran, menunjukan secara keseluruhan bahwa terdapat perbedaan hasil belajar yaitu dengan menggunahkan model mind mapping yang diberikan perlakuan, dan metode ceramah yang tidak diberikan perlakuan.

Hal ini diperkuat oleh hasil penelitian Aan Budi Santoso (2017:294) yaitu dimana hasil tes model pembelajaran mind mapping peserta didik nilai rata-rata 8,64 .. Hasil tersebut menunjukkan bahwa menggunakan model pembelajaran mind mapping berkategori baik dan harus dipertahankan.

\section{KESIMPULAN}

Berdasarkan data hasil pengujian hipotesis, maka dapat dikemukakan beberapa kesimpulan, sebagai berikut: Terdapat pengaruh model pembelajaran mind mapping terhadap hasil belajar siswa kelas X pada mata pelajaran geografi di SMA Negeri 2 Kikim Selatan

\section{DAFTAR PUSTAKA}

Muhdyahardjo, Redja. 2014. PengantarPendidikan, Depok :RajagrafindoPersada.

Salahudin, Anas. 2011. FilsafatPendidikan. Bandung : cv Pustaka Media.

Santoso, Budi, Aan. (2018) PengaruhMetode Mind Mapping TerhadapHasilBelajarSiswa Kelas V Pada Mata Pelajaran IPS. ISBN : 978-602180-70-9.

Sugiyono.

MetodePenelitianKuantitatifKualitatifdan R\&D. Bandung : Alfabeta.

Muhdyahardjo, Redja. 2014. PengantarPendidikan, Depok :RajagrafindoPersada.

Ngalimu, 2017. StrategiPembelajaran di LengkapiDengan $65 \quad$ Model PembelajaranYogyakarta :ParamaIlmu Yogyakarta.

Zarkasyi, Wahyudin. 2015. PenelitianMatematika. Bandung :ReflikaAditama. 